\title{
Kinetic Study of the Hydrolysis of p-Propoxy Aniline Phosphate Triester
}

\author{
Dr. Amit Chaudhary \\ Chemistry Department, D.S. College, Aligarh, India
}

\begin{abstract}
Kinetic study of the hydrolysis of p-propoxy aniline phosphate triester has been done in 1.0 to $6.0 \mathrm{~mol} \mathrm{dm}^{-3} \mathrm{HCl}_{\text {and }} \mathrm{pH} 1.24$ to 7.46 at $97 \pm 0.5^{\circ} \mathrm{C}$ in aqueous dioxan (v/v) mixture. The rate of hydrolysis was determined by measuring the rate of appearance of inorganic phosphate by Allen's modified colorimetric method [1]. The concentration of triester in all the kinetic runs was maintained $5.0 \times 10^{-4}$ mol. $\mathrm{cm}^{-3}$. The first order rate coefficients have been calculated using integrated form of the corresponding rate equation:

$$
K_{e}=K_{H^{+}} \cdot C_{H^{+}} \cdot \exp \cdot \mu
$$

Effects of variable factors such as temperature, pH, ionic-strength, concentrations etc. on the rate of hydrolysis of the triester have been studied to find out the participation of water molecule. Concepts such as Hammett acidity function [2]. Bunnett parameters [3]. ZuckerHammett hypothesis [4] and Bunnett-Olsen plot [5] together with Arrhenius parameters [6], comparative isokinetic data and isokinetic relationship [7-8] of other triesters of known mechanism were considered for deciding the molecularity, bond-fission and probable mechanism. The p-propoxy aniline phosphate triester has been found to be reactive via conjugate acid and neutral species but for the sake of convenience results for only conjugate acid species have been described and discussed in this study.
\end{abstract}

Keywords: hydrolysis of p-propoxy aniline phosphate triester

\section{Introduction}

The study of kinetics means, the study of motion. It covers all the important aspects of chemical reaction including mechanism. The outcome of investigations indirectly explain the path of certain complex biochemical processes, the industrial applications as well as academic significance of phosphate esters. The study of kinetics of phosphate esters having $\mathrm{C}-\mathrm{O}-\mathrm{P}, \mathrm{C}-\mathrm{N}-\mathrm{P}$ linkages cover a vast dimensions of human race development. Organophosphate esters have high applicability in industry, agriculture, horticulture, public health, plastic technology and many other related fields. The multi-dimensional importance of organophosphates leads to vigorous research and development. Also, many of the organophosphates play a key role in biological systems, whereas on the other hand some esters of neutral nature exhibit biocidal activities.

With the above developments in the field of organophosphate esters having $\mathrm{C}-\mathrm{O}-\mathrm{P}, \mathrm{C}-\mathrm{N}-\mathrm{P}$ linkages [928] investigations of the kinetic study of the acid hydrolysis of p-propoxy aniline phosphate triester have been made in a wide range of various experimental conditions at $97^{\circ} \mathrm{C}$.

\section{Experimental Investigations}

\section{(i) Preparation of the Compound}

The method of preparation of $\mathrm{p}$-propoxy aniline phosphate triester has been done by the general methods [29, 30], which involves the direct reaction of $\mathrm{POCl}_{3}$ with the present aryl amine. $15.1 \mathrm{~g}$ of pure p-propoxy aniline was dissolved in $100 \mathrm{ml}$ of dry benzene in round bottom flask. $9.0 \mathrm{ml}$. of $\mathrm{POCl}_{3}$ was added dropwise with constant stirring to the icecooled amine in about half-an-hour. The mixture was than refluxed for about 25 hours on the soxhlet heater at constant temperature of $65^{\circ} \mathrm{C}$ and then distilled at reduced pressure. The first fraction was removed by distillation at $\mathrm{b}_{50} 160^{\circ} \mathrm{C}$. The second fraction was distilled at $\mathrm{b}_{50} 160-180^{\circ} \mathrm{C}$ which was supposed to dichloridate of $\mathrm{p}$-propoxy aniline monoester. The residue left in the round bottom flask was digested in hot $5 \mathrm{~N} \mathrm{NaOH}$ solution, filtered and washed several times with boiled distilled water. It was then dried and re-crystallised with absolute ethyl alcohol to give a white crystalline solid, which was indentified to be crude triester of p-propoxy aniline with the following physical properties

(i) Melting point

(ii) Theoretical percentage of ' $\mathrm{P}$ '

$=305^{\circ} \mathrm{C}$

(iii) Observed percentage of ' $\mathrm{P}$

$=6.23$

$=6.19$

(ii) Hydrolysis Via Conjugate Acid Species

Kinetic study of the hydrolysis of tri-p-propoxy aniline phosphate has been done in the acid region from 0.1 to 6.0 mol. $\mathrm{dm}^{-3} \mathrm{HCl}$ and $\mathrm{pH} 1.24$ to 7.46 in $30 \%$ aqueous dioxin mixture at $97 \pm 0.5^{\circ} \mathrm{C}$. Pseudo first order rate coefficients have been summarised in Table 1 and Fig. I describes $\mathrm{pH}-$ $\log$ rate profile for the hydrolysis of triester.

Table 1: $\mathrm{pH}$ - $\log$ Rate Profile of TRI-p-Propoxy Aniline Phosphate at $97^{\circ} \mathrm{C}$

\begin{tabular}{|c|c|c|c|}
\hline $\mathrm{HCl}\left(\mathrm{mol} . \mathrm{dm}^{-3}\right)$ & $\mathrm{pH}$ & $\mathrm{K}_{\mathrm{e}} 10^{5}\left(\mathrm{~mol}_{\mathrm{dm}} \mathrm{.}^{-3} \mathrm{~min}^{-1}\right)$ & $5+\log \mathrm{K}_{\mathrm{e}}$ \\
\hline 6.0 & -0.778 & 50.44 & 1.70 \\
\hline 5.0 & -0.699 & 114.82 & 2.06 \\
\hline 4.0 & -0.602 & 192.62 & 2.28 \\
\hline 3.0 & -0.477 & 170.86 & 2.23 \\
\hline 2.5 & -0.400 & 154.25 & 2.19 \\
\hline 2.0 & -0.300 & 138.72 & 2.14 \\
\hline 1.0 & 0.000 & 91.89 & 1.96 \\
\hline 0.5 & 0.301 & 70.14 & 1.85 \\
\hline 0.2 & 0.700 & 50.08 & 1.70 \\
\hline 0.1 & 1.000 & 35.88 & 1.56 \\
\hline \multicolumn{4}{|l|}{ Buffers:- } \\
\hline Composition & 1.24 & 31.39 & 1.50 \\
\hline of buffers & 2.20 & 17.79 & 1.25 \\
\hline have been & 3.33 & 12.02 & 1.08 \\
\hline given in & 4.17 & 7.08 & 0.85 \\
\hline experimental & 5.60 & 4.92 & 0.69 \\
\hline \multirow[t]{2}{*}{ section } & 6.43 & 3.88 & 0.59 \\
\hline & 7.46 & 3.64 & 0.56 \\
\hline
\end{tabular}




\section{International Journal of Science and Research (IJSR) \\ ISSN (Online): 2319-7064}

Index Copernicus Value (2013): 6.14 | Impact Factor (2015): 6.391

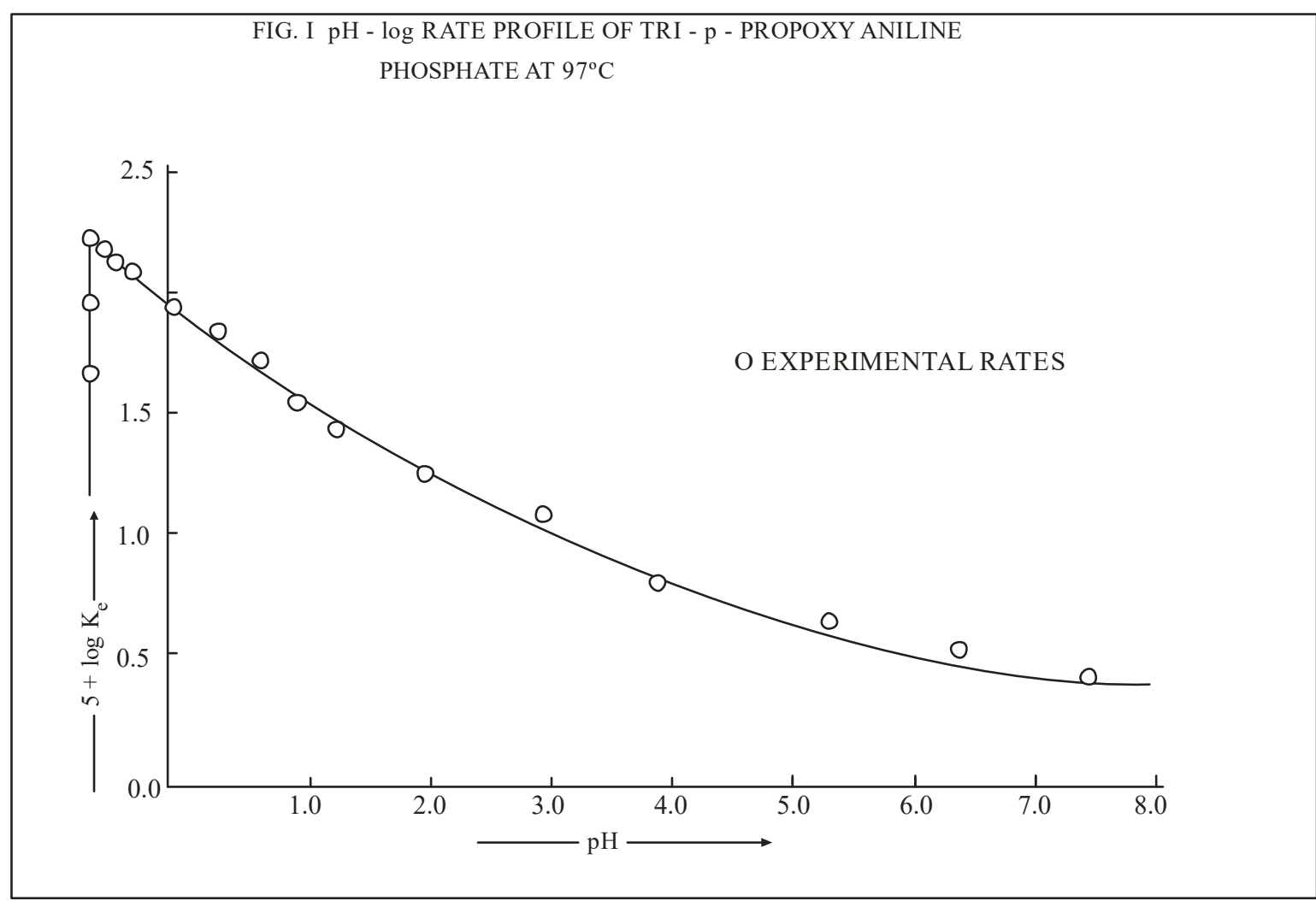

It is clear from the table that the rate of hydrolysis of the triester rises with the increases in acidity from 0.1 to 4.0 mol. $\mathrm{dm}^{-3} \mathrm{HCl}$. On further rise in acidity, the rate of hydrolysis decreases with a rate of maxima at $4.0 \mathrm{~mol} . \mathrm{dm}^{-3}$ $\mathrm{HCl}$. This rate maxima may be due to complete protonation of the triester as in amides [31, 32]. After maximum protonation the rates should be constant but lowering of rates with acid molarity may be due retarding effect of ionic strength or water activity or simultaneous effect of both.

\section{(iii) Ionic Strength Effect}

In order to examine the effect of ionic strength on the rate of hydrolysis of triester of p-propoxy aniline phosphate, systematic kinetic runs at constant ionic strength using appropriate mixtures of $\mathrm{KCl}$ and $\mathrm{HCl}$ at three different ionic strengths ie $1.0 \mu, 2.0 \mu$ and $3.0 \mu$ were used to determine the rate coefficients which have been summarised in Table-2 and FigII describes a plot between rate coefficients and acid molarities.
Table 2: Hydrolysis of TRI-p-Propoxy Aniline Phosphate at Constant Ionic Strength

\begin{tabular}{|c|c|c|c|}
\hline \multicolumn{2}{|c|}{ Composition } & \multirow{2}{*}{$\begin{array}{c}\text { Ionic } \\
\text { strength } \\
(\mu)\end{array}$} & \multirow{2}{*}{$\begin{array}{c}\mathrm{k}_{\mathrm{e}} 10^{5} \\
\left(\mathrm{~mol} . \mathrm{dm}^{-3} \mathrm{~min}^{-1}\right) \\
(\text { Obsd. })\end{array}$} \\
\hline $\begin{array}{l}\mathrm{HCl} \\
\left(\mathrm{mol} . \mathrm{dm} .^{-3}\right)\end{array}$ & $\begin{array}{c}\mathrm{KCl} \\
\left(\text { mol.dm. }^{-3}\right)\end{array}$ & & \\
\hline 0.2 & 0.8 & 1.0 & 40.12 \\
\hline 0.4 & 0.6 & 1.0 & 48.38 \\
\hline 0.6 & 0.4 & 1.0 & 61.92 \\
\hline 0.8 & 0.2 & 1.0 & 72.52 \\
\hline 1.0 & 0.0 & 1.0 & 86.28 \\
\hline 0.2 & 1.8 & 2.0 & 36.68 \\
\hline 0.5 & 1.5 & 2.0 & 48.22 \\
\hline 1.0 & 1.0 & 2.0 & 62.72 \\
\hline 1.5 & 0.5 & 2.0 & 86.43 \\
\hline 1.8 & 0.2 & 2.0 & 99.44 \\
\hline 2.0 & 0.0 & 2.0 & 134.26 \\
\hline 0.5 & 2.5 & 3.0 & 43.31 \\
\hline 1.5 & 1.5 & 3.0 & 79.00 \\
\hline 2.0 & 1.0 & 3.0 & 85.12 \\
\hline 2.5 & 0.5 & 3.0 & 99.32 \\
\hline 3.0 & 0.0 & 3.0 & 135.98 \\
\hline
\end{tabular}




\section{International Journal of Science and Research (IJSR) \\ ISSN (Online): 2319-7064}

Index Copernicus Value (2013): 6.14 | Impact Factor (2015): 6.391

\section{FIG. II HYDROLYSIS OF TRI - p - PROPOXY ANILINE PHOSPHATE AT}

CONSTANT IONIC STRENGTH AT $97^{\circ} \mathrm{C}$

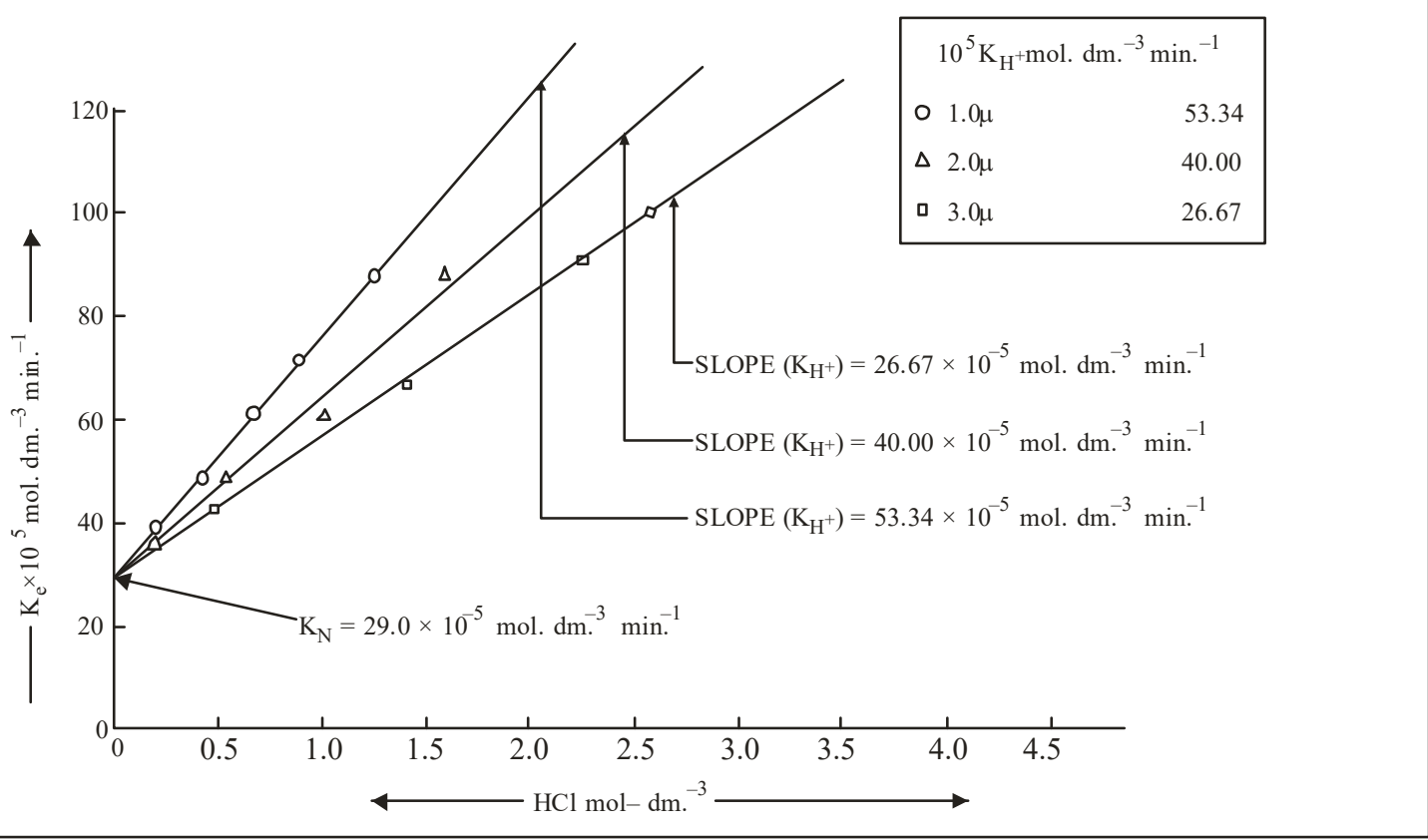

As clear from the plot three linear curves are obtained for the hydrolysis of the triester. Each curve represents the hydrolysis at that ionic strength, kinetic law for each curve may be represented as :

$$
K_{e}=K_{H^{+}} \cdot C_{H^{+}} \exp \cdot \mu
$$

Where $k_{e}$ is observed rate constant, $K_{H}^{+}$is specific acid catalysed rate constant and $C_{H}{ }^{+}$is concentration of hydrogen ion.

Since the value of slopes decreases with increasing ionic strength, the value of acid catalysed are subjected to negative effect of ionic strength.

In case of tri-p-propoxy aniline phosphate there is a constant contribution of neutral species towards the overall rates of hydrolysis of triester. Then, the equation (1) will be represented as.

$$
\begin{gathered}
K_{e}=K_{H^{+}} \cdot C_{H^{+}} \cdot \exp \cdot \mu+K_{N} \\
\text { or }\left(K_{e}=\text { Acid Rate }+ \text { Neutral rate }\right)
\end{gathered}
$$

\section{Conclusion}

It is clear from the results that there is a fairly good agreement between observed and theoretical rates upto 4.0 mol. $\mathrm{dm}^{-3}$. The observed deviation in acid solution (5.0 and $\left.6.0 \mathrm{~mol} . \mathrm{dm}^{-3} \mathrm{HCl}\right)$ can be removed by introducing water activity as a parameter.

\section{(iv) Molecularity}

The molecularity of the acid catalysed hydrolysis of $\mathrm{p}-$ propoxy aniline triester has been determined by the concepts such as Hammett relationship [2], Zucker-Hammett hypothesis [4], Bunnett parameters [3] and Bunnett-Olsen parameters [5] (figs. not shown). The slope value of Hammett plot is 0.286 which is far from unity and that of Zucker-Hammett curve is 0.5 which is round about unity, which indicates bimolecular hydrolysis of the triester Bunnett and Bunnett-Olsen parameters whose slope values are $\omega=5.3 \& \omega *=12.5$ (Bunnett) and $\phi \square=1.42$ (Bunnettolsen), also supports bimolecular reaction.

Bimolecular nature of hydrolysis of the triester has also been supported by Arrhenius parameters [6] at 3.0 and $5.0 \mathrm{~mol}$. $\mathrm{dm}^{-3} \mathrm{HCl}$, summarised in Table. 3. The value of activation energy is less than $25 \mathrm{kcal} / \mathrm{mole}$, the value of frequency factor $(\lambda)$ has the power less than 12 and the value of entropy of activation is negative value.

\begin{tabular}{|c|c|c|c|}
\hline \multirow{2}{*}{$\begin{array}{c}\mathrm{HCl} \\
\left(\text { mol.dm. }^{-3}\right)\end{array}$} & \multicolumn{2}{|c|}{ Parameters } & Entropy \\
\hline & $\begin{array}{l}\text { Energy of activation } \\
\text { (E) K. cals/mole }\end{array}$ & $\begin{array}{l}\text { Frequency factor } \\
(\lambda) \sec ^{-1}\end{array}$ & $-\Delta \mathrm{s}^{\neq}$(e.u.) \\
\hline 3.0 & 19.67 & $11.91 \times 10^{6}$ & 28.58 \\
\hline 5.0 & 22.42 & $33.47 \times 10^{7}$ & 21.95 \\
\hline
\end{tabular}

Table 3: Arrhenius Parameters for the Hydrolysis of TRI -pPropoxy Aniline Phosphate aT $97^{\circ} \mathrm{C}$

It may be concluded from the results, that magnitude of Arrhenius parameters fall in the range of bimolecular reactions via conjugate acid species.

Further, the effect of solvent on the rate of hydrolysis of conjugate acid species of the triester has been observed to seek another support for the molecularity of the reaction. A series of kinetic runs has been made using various compositions of water dioxan mixtures at 3.0 and $5.0 \mathrm{~mol}$. $\mathrm{dm}^{-3} \mathrm{HCl}$, which are summarised in Table -4 . 


\section{International Journal of Science and Research (IJSR) \\ ISSN (Online): 2319-7064 \\ Index Copernicus Value (2013): 6.14 | Impact Factor (2015): 6.391}

Table 4: Solvent Effect on the Hydrolysis of TRI -pPropoxy Aniline Phosphate at $97^{\circ} \mathrm{C}$

\begin{tabular}{|c|c|c|c|}
\hline $\begin{array}{c}\mathrm{HCl} \\
\left(\mathrm{mol}_{\mathrm{dm}}{ }^{-3}\right)\end{array}$ & $\begin{array}{c}\text { percentage of } \\
\text { Water } \\
(\mathbf{v} / \mathbf{v})\end{array}$ & $\begin{array}{c}\text { percentage of } \\
\text { Dioxan } \\
(\mathrm{v} / \mathbf{v})\end{array}$ & $\begin{array}{c}\text { Ke. } 10^{5} \\
(\mathrm{~mol} . \mathrm{dm} . \\
\left(\mathrm{Obsd} \cdot \mathrm{min}^{-1}\right)\end{array}$ \\
\hline 3.0 & 70.0 & 30.0 & 170.86 \\
\hline 3.0 & 60.0 & 40.0 & 174.30 \\
\hline 3.0 & 40.0 & 60.0 & 177.92 \\
\hline 5.0 & 70.0 & 30.0 & 114.82 \\
\hline 5.0 & 60.0 & 40.0 & 118.62 \\
\hline 5.0 & 40.0 & 60.0 & 121.28 \\
\hline
\end{tabular}

The change in rate with the change in solvent of a reaction has made to determine the nature of transition state and hence the molecularity of the reaction. The observed significant rise in the rates of hydrolysis favours the formation of transition state in which charge is created and dispersed in the rate determining step in the system. Hence the reaction proceeds bimolecularity via conjugate acid species.

\section{(iv) Bond-Fission}

The bimolecular nature of hydrolysis of p-propoxy aniline phosphate triester as determined, may involve either $\mathrm{P}-\mathrm{N}$ or $\mathrm{C}-\mathrm{N}$ bond fission. The probability of former seems to be more because of the stability of intermediate formed during the progress of the reaction. In this fission, amine molecule formed as an intermediate will be stabilised to a large extent by mesomeric effect. The probability of $\mathrm{P}-\mathrm{N}$ bond fission is also supported by comparative isokinetic data of other triesters which have been summarised in Table -5 .

Table 5: Comparative Kinetic Rate Data for the Hydrolysis of Some Phosphate Triesters Via Their Conjugate Acid Species

\begin{tabular}{|l|l|c|c|c|c|c|c|c|}
\hline S. No. & $\begin{array}{l}\text { Phosphate } \\
\text { di-ester }\end{array}$ & medium & Temp. & $\begin{array}{c}\text { E.K. } \\
\text { cals/mole }\end{array}$ & $-\Delta \mathrm{s}^{*}(\mathrm{e} . \mathrm{u})$. & $\begin{array}{c}\text { Bond } \\
\text { fission }\end{array}$ & Molecularity & Ref. \\
\hline 1. & $\mathrm{p}$ - toluidine & 80 & 4.0 & 15.08 & 25.85 & $\mathrm{P}-\mathrm{N}$ & 2 & 33 \\
\hline 2. & $\mathrm{~m}-$ toluidine & 80 & 4.0 & 14.62 & 32.92 & $\mathrm{P}-\mathrm{N}$ & 2 & 33 \\
\hline 3. & $\mathrm{p}$ - nitro aniline & 98 & 3.0 & 15.25 & 42.71 & $\mathrm{P}-\mathrm{N}$ & 2 & 34 \\
\hline 4. & $\mathrm{p}-$ chloro aniline & 98 & 4.0 & 11.44 & 46.68 & $\mathrm{P}-\mathrm{N}$ & 2 & 35 \\
\hline 5. & $\mathrm{P}-\mathrm{OCH}_{3}$ aniline & 6.5 & - & 18.67 & 22.70 & $\mathrm{P}-\mathrm{N}$ & 2 & 36 \\
\hline 6. & $\mathrm{P}-\mathrm{OC}_{2} \mathrm{H}_{5}$ aniline & 98 & - & 7.59 & 52.20 & $\mathrm{P}-\mathrm{N}$ & 2 & 37 \\
\hline 7. & $\begin{array}{l}\text { tri-2, 6-dimethyl } \\
\text { phenyl }\end{array}$ & 98 & - & 21.59 & 19.19 & $\mathrm{P}-\mathrm{O}$ & - & 38 \\
\hline 8. & $\begin{array}{l}2,4,6-\text { tri bromo } \\
\text { phenyl }\end{array}$ & 98 & - & 20.59 & 22.28 & $\mathrm{P}-\mathrm{O}$ & - & 39 \\
\hline 9. & cyclo hexylamine & 50 & 1.0 & 15.96 & 37.47 & P-N & 2 & 40 \\
\hline 10. & p- propoxy aniline & 97 & 3.0 & 19.67 & 28.58 & P-N & - & This work \\
\hline & & & 5.0 & 22.42 & 21.95 & P-N & - & This work \\
\hline
\end{tabular}

$\mathrm{P}-\mathrm{N}$ bond fission of the conjugate acid species of the triester have been invariably supported by the Fig. III, which describes a plot between activation energy $(E)$ and entropy of activation $(-\Delta s \neq)$. The plot is linear covering almost all the points of similar phosphate triester. The point of the conjugate acid species of $\mathrm{p}$-propoxy aniline phosphate triester lies on the straight line of other similarly substituted phenyl phosphate triesters which undergo $\mathrm{P}-\mathrm{N}$ rather than $\mathrm{C}-\mathrm{N}$ bond fission. Hence $\mathrm{p}-$ propoxy aniline phosphate undergo hydrolysis bimolecularly via $\mathrm{P}-\mathrm{N}$ bond fission. 


\section{International Journal of Science and Research (IJSR) \\ ISSN (Online): 2319-7064}

Index Copernicus Value (2013): 6.14 | Impact Factor (2015): 6.391

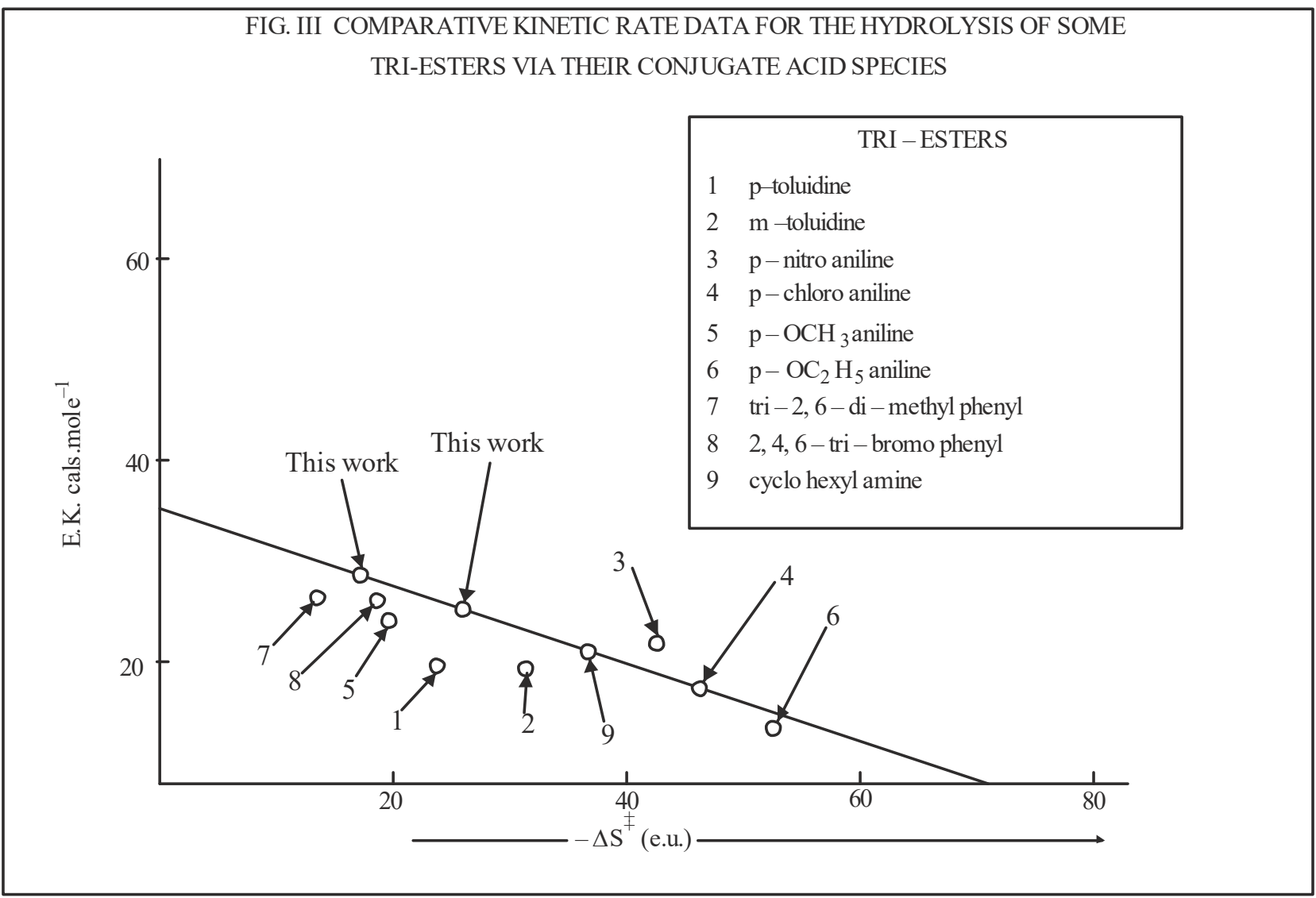

\section{(vi) Mechanism}

On the basis of all the above observations and experimental evidences, mechanism of the acid catalysed hydrolysis of $\mathrm{p}-$ propoxy aniline phosphate triester may proceed through the following steps :

(a) Formation of conjugate acid species by fast pre-equilibrium proton transfer :
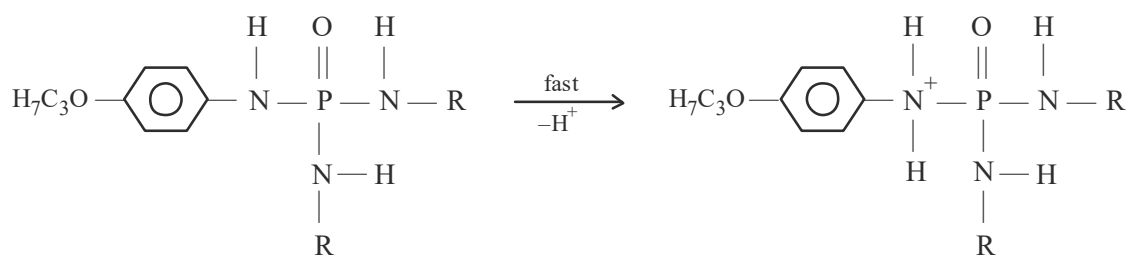

(b) Bimolecular nucleophilic attack of water on phosplhorus $S_{N} 2(P)$ :

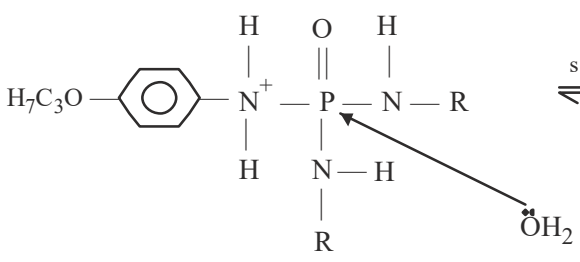

(Conjugate acid species)

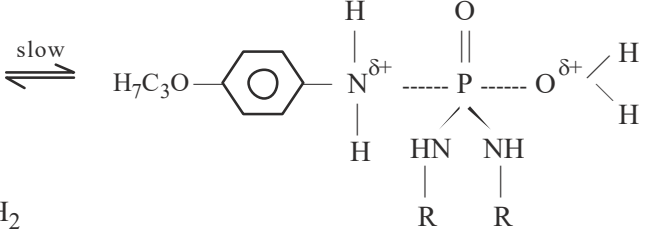

(Transition state)<smiles>[R]NN([R])P(=O)(N[R])[OH+][PH]</smiles>

Volume 5 Issue 4, April 2016 
International Journal of Science and Research (IJSR)

ISSN (Online): 2319-7064

Index Copernicus Value (2013): 6.14 | Impact Factor (2015): 6.391

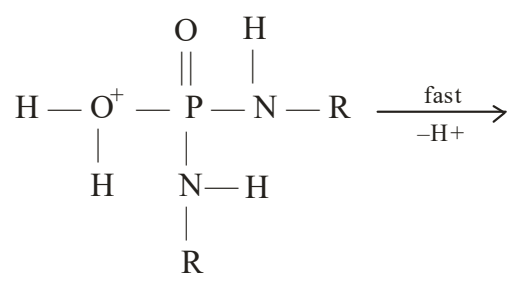<smiles>[R]NP(=O)(O)N[R]</smiles>

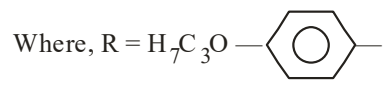

\section{References}

[1] Allen, R.J.L., Biochem J. 34, 858 (1940).

[2] Hammett, L.P. and Dyrup, A.J., J. Am. Chem. Soc., 54, 2721 (1932).

[3] Bunnett, J.F., J. Am. Chem. Soc., 83, 4956, 4968, 4973, 4978 (1961).

[4] Zucker, L. And Hammett, L.P., J. Am. Chem. Soc., 61, 2779, 2785 (1939).

[5] Bunnett, J. F. And Olsen. F. P., Can. J. Chem. 44 (1966).

[6] Arrhenius, S. Z. Physik. Chem. 4, 226 (1989).

[7] Bunnett, J. F., “Technique of Organic Chemistry”. Vol III ed. A. Weisaberger, "Rates and mechanism of reatiosn”, Part I, Ch VI, Pg 177, (1961).

[8] Kosower, E.M., "an introduction to physical organic chemistry”, John Wiley and sons, INC, New York and London 51 and 68 (1968).

[9] Bhoite, A. K. "Kinetic Study of hydrolysis of compounds containing $C$, Nand $P(C-N-P)$ linkage" (1977).

[10] Tewari, B. K., Ph.D. Thesis, Agra Univ. Agra (1985).

[11] Kushwaha, R. S. Tiwari, B. K. And P. Singh. Acta Ciencia Indica, Vol. XII C No. 4, 207 (1986).

[12] Kushwaha, R. S., Tiwari, B.K. and P. Singh J. of Indian Council of Chemists, Vol. IV, No. 3 (1989).

[13] Kushwaha, R. S. and Mhala. M.M. Indian J. Chem. Vol. 28, A, 420-421 (1989).

[14] Shivdhonkar, Vaishali, Ph. D. Thesis, Jiwaji, Univ., Gwalior (1997).

[15] Singh Pratap and Kumar Abanish, J. of Indian Coundil of Chemists, Vol. 28, No. 1, Pg 56-69 (2011).

[16] Chaudhary Gaurav, Ph.D. Thesis, Dr. B. R. A. Univ. Agra (2013).

[17] Verma Devdutt, Ph.D. Thesis, Dr. B. R. A. Univ. Agra (2013).

[18] Patel Anil, Ph.D. Thesis, Dr. B. R. A. Univ. Agra (2013).

[19] Kumar Abanish, Ph.D. Thesis, Dr. B. R. A. Univ. Agra (2013).

[20] Kumar Raman, Ph.D. Thesis, Dr. B. R. A. Univ. Agra (2013).

[21] Singh Sanchita, Ph.D. Thesis, Dr. B. R. A. Univ. Agra (2014).

[22] Saxena Amrita, Ph.D. Thesis, Dr. B. R. A. Univ. Agra (2014).

[23] Kumar Abanish, Pak. J. Sci. Ind. Res. Ser. A : Phys. Sci. 58 (3) 117-121 (2015).

[24] Chaudhary Amit, IJIET, Vol. 6 Issue Oct. 2015, Pg 3950 (2015).
[25] Chaudhary Amit, IJERGS, Vol. 3 Issue 6 Pg. 342-356 (2015).

[26] Chaudhary Amit, IJMRD, Vol. 2 Issue 11, Pg 482-487 (2015).

[27] Chaudhary Amit, IJSR, Vol. 5 Issue 1, Jan. 2016, Pg 1358-1363 (2016).

[28] Chaudhary Amit, IJSR, Vol. 5 Issue 3, March 2016, Pg 715-720 (2016).

[29] Paul otto, Ber. 28, 816 (1895).

[30] Rudert, P., Ber., 26, 565 (1893)

[31] Edward, J. T. And Meacock, S. C. R. D., J. chem.. Soc., 2000 (1957).

[32] Rosenthol, D. And Taylor, T. I.,J. Am. Chem.. Soc., 79, 2684 (1957).

[33] Bhoite, A. K., Ph.D. Thesis, Jiwaji Univ., Gwalior (1977).

[34] Jain, P., Ph.D. Thesis, Jiwaji Univ., Gwalior (1982).

[35] Agarwal (Miss) N. Unpublished Data, Jiwaji Univ., Gwalior.

[36] Sahani (Miss) Veena, Ph.D. Thesis, Jiwaji Univ., Gwalior (1984).

[37] Bhadoria, A. K. S., Ph.D. Thesis, Jiwaji Univ., Gwalior (1982).

[38] Mhala, M. M., Prabha (Miss.) S., Indian J. of Chem., Vol. 10, 1073-1076 (1972).

[39] Chaudhary. S., Ph.D. Thesis, Jiwaji Univ., Gwalior (1974).

[40] Chauhan, K. P. S., Ph.D. Thesis, Jiwaji Univ., Gwalior (1972). 